\title{
MODELLING PERCEIVED PEDESTRIAN LEVEL OF SERVICE OF SIDEWALKS: A STRUCTURAL EQUATION APPROACH
}

\author{
Geetha Rajendran BIVINA ${ }^{1^{*}}$, Manoranjan PARIDA ${ }^{2}$ \\ Dept of Civil Engineering, Indian Institute of Technology, Roorkee, India
}

Received 30 October 2017; revised 30 January 2018; accepted 4 July 2018

\begin{abstract}
A disparity between developed and developing countries is not only in terms of economy and geography, but also on pedestrians' perceptions and expectations about the level of service of sidewalks. Therefore, it is paramount to find the effect of various built environment measures that impact perceived Pedestrian Level Of Service (PLOS) in context of developing nations. This study investigates the most influential factors of built environment that affect perceived PLOS of sidewalks in Indian context. This is one of the first studies in India that utilize Structural Equation Modelling (SEM) technique to assess pedestrian satisfaction and thereby qualitative PLOS of sidewalks. A total of 502 personal interviews was conducted to extract the pedestrian perception about the quality of sidewalks of Thiruvananthapuram city, a typical Indian city. The results identified four latent exogenous constructs named "Safety", "Security", "Mobility and infrastructure" and "Comfort and convenience" that represent the main aspects of PLOS of sidewalks among which factors of security has exhibited highest loading $(\lambda=0.60)$. The study identified that parameters like police patrolling, street lighting, cleaner sidewalks, sidewalk obstructions, sidewalk surface have an evident impact on the level of service of sidewalks. The results of the study provide a significant information for interpreting the aspects of the walking environment that mainly influences the PLOS. This information can help city planners to prepare new strategies, policy interventions that enhance the quality of sidewalks and thus making the city more walkable.
\end{abstract}

Keywords: pedestrian, structural equation modelling, level of service, sidewalks, satisfaction.

\section{Introduction}

Walking is one of the most basic and sustainable modes of transport, and has several social, individual and environmental benefits attached to it, that include social equity, health and wellness, reduced greenhouse emission, etc. (Vale, Pereira 2016). Increasing awareness of these benefits of walking has generated interest in recognizing built environment factors that facilitate walking. These factors exist in different geographical scale such as, macro scale and micro scale, which is collectively termed as "walkability". The elements like land use mix, density, etc. exist on a larger scale or macro scale; other factors like pedestrian facilities, sidewalk quality, etc. exists at a street level scale or microscale (Barker 2012). The study conducted by Clifton et al. (2007) revealed the importance of microscale factors of the environment in facilitating or constraining walking. Researchers have assessed a number of factors of built environment such as sidewalk availability and width, sidewalk quality, crossing facilities, street lighting, etc. and the corresponding effects of these factors on walking and
Pedestrian Level Of Service (PLOS). Many indices have been developed by researchers to quantify walkability as a single measure of a number of these attributes. Some of the audit tools, models and indices developed are PLOS models, Walk Score (2018), Pedestrian Environmental Data Scan (PEDS) (Clifton et al. 2007), Systematic Pedestrian and Cycling Environmental Scan (SPACES) (Pikora et al. 2002), etc. This paper attempts to identify the most influential built environment factors on perceived level of service of sidewalks in Thiruvananthapuram city, which is the capital city of Kerala (India). A personal interview has been conducted with pedestrians in the city, with the aim of recognizing such factors, by utilizing Structural Equation Modelling (SEM). Another objective of the paper is to recognize which unobserved latent variables are constituting to the main characteristics of PLOS. SEM techniques has been widely used to assess service quality and customer satisfaction of bus or metro systems. This is one of the first study in India that utilizes SEM technique

${ }^{\star}$ Corresponding author. E-mail: biviplna@gmail.com 
to analyse pedestrian satisfaction and thereby qualitative PLOS of sidewalks. The findings of this study can provide valuable information to planners and experts to understand the unobserved latent aspects of the PLOS of sidewalks. This research will can help to plan new strategies and future interventions to upgrade the service quality of sidewalks by improving the factors influencing it and thus making the city more walkable.

\section{Literature review}

\subsection{PLOS and satisfaction}

The study mainly focuses on PLOS model that is used to quantify walkability. PLOS is the improvement in service quality of sidewalk facilities that leads to a higher pedestrians' satisfaction eliciting higher walkability of that region. Thus, most of the approaches for measuring the service quality of sidewalks uses PLOS (Asadi-Shekari et al. 2013). Modelling of perceived PLOS of sidewalks brings insight to pedestrian's satisfaction in using the facility, i.e. walking environment quality is based on pedestrians' degree of satisfaction with walking needs as a whole. According to Johnson et al. (1995), the term "satisfaction" is a function of user's expectations and perceived performance in any given period. Thus, if pedestrians' need and expectation are met, they will exhibit positive walking behaviour. The level of pedestrian satisfaction is related to the level of service offered by the pedestrian facilities. However, the approaches to evaluate the level of satisfaction experienced by pedestrians are limited. Kim et al. (2013) identified the importance of including pedestrian satisfaction instead of pedestrian density to assess the level of service in Highway Capacity Manual (Kim et al. 2013). Said et al. (2017) identified that general aspects of walking environment such as sidewalk quality, cleanliness, blockage, etc. have an evident influence on the level of satisfaction. Zainol et al. (2014) used pedestrian level of satisfaction to measure walkability by evaluating the users' perception on pedestrian facilities. Kim et al. (2014) found that micro scale factors of walking environment have a significant influence on pedestrian satisfaction. The methodology proposed by Jensen (2007) to assess PLOS was based on the ratings given by pedestrians with respect to how satisfied they would be while walking. Even though it is difficult to operationalize the concept of level of pedestrians' satisfaction, its relation to built environment factors that affects walking helps in disclosing the potential factors for improving the walk environment. Hence, it is important to assess the level of satisfaction and interpret how it is affected by the various attributes that ascertain the level of service of pedestrian facilities.

\subsection{Factors affecting PLOS}

Past studies identified many factors that affect PLOS and walkability. Previous studies on PLOS aimed at only the quantitative measures that considered factors like pedes- trian speed, flow and density. The quantitative PLOS model developed so far tends to neglect qualitative attributes of sidewalks. A limited number of studies have considered qualitative factors such as comfort, safety, walking environment, and disability issues, when compared to quantitative factors on PLOS. An Indian code, i.e. Indian Road Congress (IRC: 103-2012) reported the qualitative attributes to be considered for assessing quality of sidewalks, but there is no mention about the effect of these qualitative attributes on the PLOS. Table 1 summarizes past researches done for PLOS. Most of the PLOS models developed were based on US conditions that cannot be generalized for universal contexts, especially for developing countries. The economic constraints in developing countries result in limited fund allocation for pedestrian infrastructure and can cause poor walking environment. Hence, the degree of pedestrians' satisfaction of built environment factors of walking is different for pedestrians of developing countries. The economic constraints in developing countries result and can cause poor walking environment in limited fund allocation for pedestrian infrastructures and can cause poor walking environment the degree of pedestrians' satisfaction of built environment factors of walking is different for pedestrians of developing countries. This disparity between economy and geography among developed and developed countries can also vary their needs and expectations on built environment factors that affects walking. Therefore, it is paramount to find the effect of various built environment measures that impact perceived PLOS in the context of developing nations.

\section{Methodology}

\subsection{SEM}

SEM methodology is a powerful analysis technique that explains the relationships between multiple variables. The SEM can examine more than one relationship at a time, which is different from other multivariate tests (Hair et al. 2013). SEM has many applications in research of different fields such as social sciences, education, psychology, statistics, economics, etc. Literature also reports the use of SEM in transportation studies (Eboli, Mazzulla 2007; De Oña et al. 2013; Golob 2003). Measurement model and structural model are the two main components of SEM. The measurement model examines the relationship between measured items and the latent, whereas structural model measures the inter-relationship between the latent variables. To properly conceptualize the model, latent variables are divided into two types: endogenous and exogenous variables. The SEM is defined by following basic model (Bollen 1989):

$$
\eta=B \cdot \eta+\tau \cdot \xi+\zeta,
$$

where: $\eta-m \times 1$ vector of the latent endogenous variables; $B-m \times m$ matrix of coefficients $\beta$ associated with the latent endogenous variables; $\tau-m \times n$ matrix of the coefficients 
Table 1. PLOS studies

\begin{tabular}{|l|l|l|l|}
\hline \multicolumn{1}{|c|}{ Author } & Country & \multicolumn{1}{c|}{ Methods } & \multicolumn{1}{c|}{ Factors considered } \\
\hline $\begin{array}{l}\text { Mitra-Sarkar } \\
\text { (1994) }\end{array}$ & US & Scoring system & Convenience, comfort, safety, security, continuity, system coherence and attractiveness \\
\hline Khisty (1994) & US & Scoring system & Comfort, convenience, continuity, attractiveness, system coherence, safety, security \\
\hline Dixon (1996) & US & Scoring system & $\begin{array}{l}\text { Path conflicts, amenities, motor vehicle level of service, maintenance problems, } \\
\text { provision for basic facilities and provision for multiple modes }\end{array}$ \\
\hline $\begin{array}{l}\text { Landis } \text { et al. } \\
\text { (2001) }\end{array}$ & US & $\begin{array}{l}\text { Ordinary least } \\
\text { regression }\end{array}$ & $\begin{array}{l}\text { Lateral separation factors, traffic volume, speed of the vehicle, driveway access } \\
\text { frequency and volume }\end{array}$ \\
\hline Gallin (2001) & Australia & Scoring system & $\begin{array}{l}\text { Sidewalk width, sidewalk surface, comfort, walk environment, potential to vehicle } \\
\text { conflict, crossing facilities and pedestrian volume }\end{array}$ \\
\hline $\begin{array}{l}\text { Muraleetharan } \\
\text { et al. } \text { (2004) }\end{array}$ & Japan & $\begin{array}{l}\text { Ordinary least } \\
\text { regression }\end{array}$ & Sidewalk width \& separation, pedestrian volume, flow rate and bicycle events \\
\hline Jensen (2007) & Germany & $\begin{array}{l}\text { Cumulative } \\
\text { logit model }\end{array}$ & $\begin{array}{l}\text { Sidewalk width, walking environment, pedestrian volume, parked vehicle, } \\
\text { bicycle track width, buffer area and landscape }\end{array}$ \\
\hline $\begin{array}{l}\text { Parida } \text { et al. } \\
\text { (2007) }\end{array}$ & India & Scoring system & $\begin{array}{l}\text { Footpath width, footpath surface, continuity, comfort, safety, encroachment, potential } \\
\text { to vehicle conflict, crossing facilities, walking environment and pedestrian volume }\end{array}$ \\
\hline $\begin{array}{l}\text { Dowling } \text { et al. } \\
\text { (2008) }\end{array}$ & US & $\begin{array}{l}\text { Ordinary least } \\
\text { regression }\end{array}$ & $\begin{array}{l}\text { Traffic volume, pavement width, shoulder width, on street parking, buffer width, } \\
\text { sidewalk presence, sidewalk width, number of through lanes, traffic speed }\end{array}$ \\
\hline $\begin{array}{l}\text { Asadi-Shekari } \\
\text { et al. }(2013)\end{array}$ & Malaysia & $\begin{array}{l}\text { Scoring system } \\
\text { (guiding), tactile pavement (warning), signal, seating area, drinking fountain, } \\
\text { curb ramp, ramp, grade, signal, bollards, lighting, driveway, traffic speed, buffer, } \\
\text { traffic lanes, crossing, facilities, furniture }\end{array}$ \\
\hline
\end{tabular}

associated with the latent exogenous variables; $\xi-n \times 1$ vector of the latent exogenous variables; $\zeta-m \times 1$ vector of error terms associated with the endogenous variables.

The measurement model can be represented by basic equation as follows:

$$
\begin{aligned}
& x=\Lambda_{x} \cdot \xi+\delta \\
& y=\Lambda_{y} \cdot \eta+\varepsilon,
\end{aligned}
$$

where: $x$ - column $q$ vectors related to the observed exogenous variables; $\delta$ - column $q$ vectors related to the observed exogenous errors; $\Lambda_{x}-q \times n$ structural coefficient matrix for the effects of the latent exogenous variables on the observed ones; $y$ - column $p$ vectors related to the observed endogenous variables; $\varepsilon$ - column $p$ vectors related to the observed endogenous errors; $\Lambda_{y}-p \times m$ structural coefficient matrix for the effects of the latent endogenous variables on the observed ones.

SEM can be estimated using different covariance analysis techniques like Generalized Least Squares (GLS), Maximum Likelihood (ML), Weighted Least Squares (WLS), etc. Among the various covariance analysis methods, ML method is the most frequently used one.

The study deals with latent constructs like comfort, safety, security, etc. that cannot be measured directly from the field but can be measured using a set of items in a questionnaire called observed variables or measured variables. Since the Ordinary Linear Regression (OLR) techniques could not entertain latent constructs, SEM has been employed for the analysis. Using SEM, it is easy to establish the relationship among these constructs together with their respective items in the model and analyse them simultaneously (Awang 2012). SEM incorporates the measurement errors associated with the data (perception data) in the model that makes it different from other OLR techniques (Goldberger 1972). Thus, the SEM is an appropriate statistical technique for the present study.

\subsection{Phases in analytical procedure}

The research followed a step-by-step methodology to develop SEM model. The process consists of mainly five phases.

First phase of the study included a pilot study to capture the service quality perceptions of different aspects of sidewalks in Thiruvananthapuram and to assess the pedestrians' attitudes towards the service. The questionnaire was developed carefully choosing questions from previous studies and previous walkability survey instruments. The pilot survey was conducted to determine the time taken to answer the questionnaire and the degree of complexity of the questions being asked to respondents. After the pilot study, the questionnaire was modified by removing and replacing some factors on the basis of feedback provided by pedestrians.

Second phase, the interview was conducted using modified questionnaire. Simple random sampling was adopted to conduct the survey where responses were taken from offices, households, public spaces, etc. As the pedestrians were not willing to give face-to-face interview at sidewalks due to summer heat, the responses were collected from their residences, offices and other public spaces where they gather. So almost 502 complete questionnaire samples were collected.

Third phase of the study conducts an Exploratory Factor Analysis (EFA) to assess the pedestrian satisfaction 
scores. This process was based on Principal Component Analysis (PCA) and reliability analysis using Cronbach's alpha. The exploratory analysis is used in determining relationships among the explanatory variables, assessing the direction of relationships between explanatory and outcome variables and in grouping different attributes according to pedestrians' perceptions. Cronbach's alpha is a technique to measure the reliability of the questionnaire with multiple Likert scale questions, which are used to measure latent variables (Gliem, J. A., Gliem, R. R. 2003) where value with 0.70 or higher shows good reliability. It estimates how well a set of questions measures a single unidimensional factor. Adequacy check was done by performing Kaiser-Meyer-Olkin (KMO) test. KMO values between 0.8 and 1 indicate that sampling is adequate (Gliem, J. A., Gliem, R. R. 2003).

In the fourth phase, normality test was performed to check the normality of the data by measuring skewness and kurtosis for every item. The absolute value of skewness and kurtosis between -1.50 to +1.50 show that data set is normally distributed (Muthén, Kaplan 1985). Normality test confirms the variable eligibility for SEM approach.

Fifth phase included SEM or path analysis to test the predicted relationships between constructs of proposed model. The base model was developed using EFA was used to model perceived PLOS of sidewalks as a function of covariates through SEM. The ML method is used to estimate structural equation system. The SEM analyse the structural coefficients and fit indexes. A variety of indexes is used to check the goodness of fit of the structural models from which at least one of the fit index from each category of model fit has to be used (Hair et al. 2013; Hooper et al. 2008; Holmes-Smith et al. 2006). The final model is obtained by continuously reiterating the model till acceptable fit indices are obtained.

\section{Study area}

Thiruvananthapuram, the capital of the Indian state, Kerala is selected as the study area. It is one of the most populous and largest cities in Kerala with about 1.6 million population (CPD 2011). Thiruvananthapuram city has a well-developed and organized transport infrastructure, especially the road and rail networks. Like many other million plus cities in Asia, lack of effective planning and high population growth had induced various transportrelated problems in Thiruvananthapuram city center. Lack of quality pedestrian facilities has resulted in deteriorated walking environment in the city. The studies have found that out of 36 roads selected for a pedestrian study, $90 \%$ of the roads had sidewalks, but their non-utilization makes their quality questionable (NATPAC 2014). At many instances, pedestrians are forced to cross the road to the sidewalk on the opposite side or get down to the road because of poor sidewalk quality. A total of 10 locations (corporation zones) from different land uses was selected from the Central Business District (CBD) area of the city. The selection of zones done in such a way that study locations could represent the entire population of the city also including all land use types. The zones included in the study are Keshavadasapuram, Ulloor, Chalai, Medical College, Pattom, Palayam, Nalanchira, Poojapura, East Fort and Thampanoor. The study locations are displayed in Figure 1.

\section{Data collection}

Simple random sampling was adopted to capture the responses. Personal interviews were conducted for sidewalks from ten zones of the city on March 2017, to capture the pedestrians' attitudes towards various service quality attributes of sidewalks.

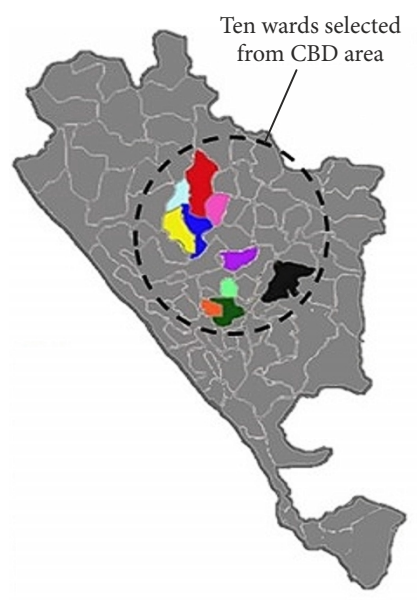

Thiruvananthapuram district
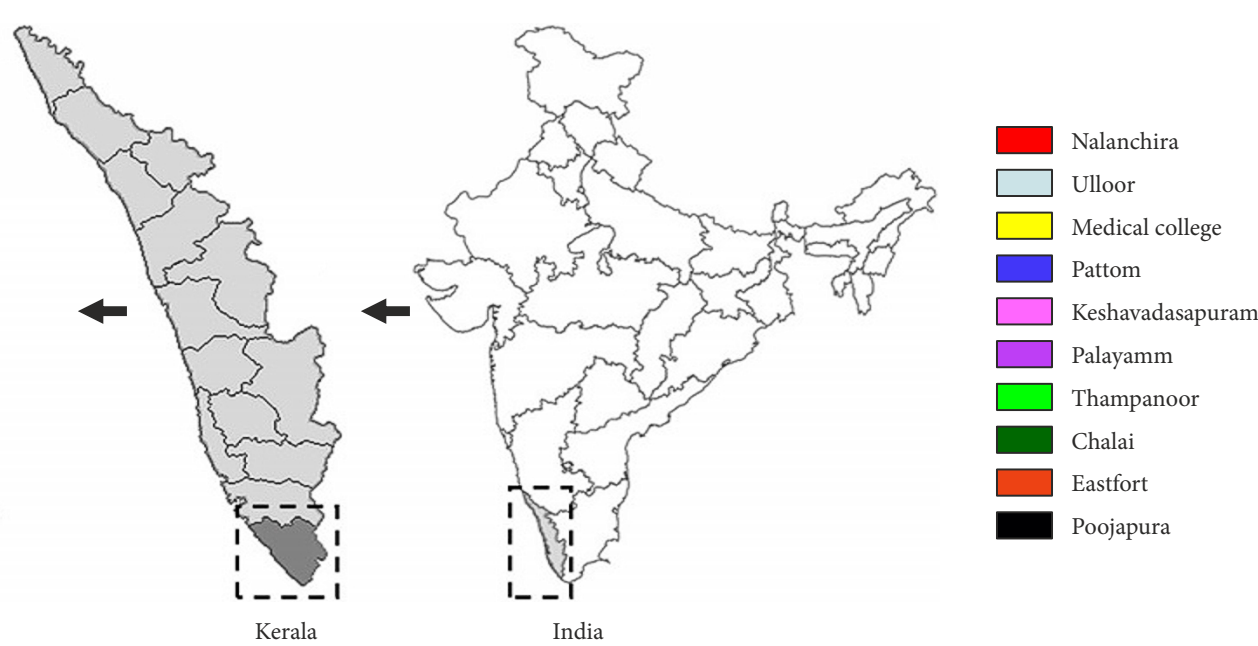

Figure 1. Map showing study locations 


\subsection{Sampling design}

The sample size was calculated from the population of walk trips produced at selected study area at a confidence interval of $95 \%$ and a $5 \%$ margin of error. There are three factors such as variability of the population, the degree of precision and population size that significantly affect the determination of suitable sample size (Krejcie, Morgan 1970). Walking accounts for $17 \%$ of total trips produced in the study area (NATPAC 2014). The minimum number of sample size obtained is 384 and about 502 responses were collected from various households, offices and public spaces. The responses collected from each zones varied based on zone's population as more samples were collected from zones with high populations:

$$
S=\frac{\chi^{2} \cdot N \cdot P \cdot(P-1)}{d^{2} \cdot(N-1)+\chi^{2} \cdot P \cdot(P-1)},
$$

where: $S$ - required sample size; $\chi^{2}$ - the table value of chi-square at anticipated confidence interval (3.8342); $N$ population size (the number of walk mode trips i.e. $17 \%$ of the total population); $P$ - population proposition of crossing trip; $d$ - the degree of accuracy as a proposition (0.05). The collected questionnaire survey sample in this study is more or equal to the required sample size $S$.

\subsection{Design of questionnaire}

Various steps were adopted to design the questionnaire. First step of designing questionnaire was to decide the information that has to be collected accordingly with the prescribed objectives. A rough listing of questions were made that were included in the questionnaire. The questions were made as comprehensive as possible in the listing. The phrasing of questions were defined such that questions appear close to the point. As the next step, the response format was developed and this study adopted Likert scale responses that gave rating in the scale of 1 to 5 . Now the questions were arranged in sequences that would help in bringing logic and flow to the interview. The questionnaire was finalised by giving clear introduction of the study. Finally, pretesting and revision of questionnaire was done by conducting a pilot study. A pilot study of 50 samples were collected to determine the degree of complexity and total time taken to answer the questions. After the pilot study, the limitations and inefficiencies of questionnaire were identified. Then the questionnaire was modified by removing and replacing some factors and changing the pattern of questions on the basis of feedback provided by pedestrians and experts. The study used internal consistency to examine the reliability of items in the proposed survey instrument. It estimates how well the set of questions measures the main factor. Cronbach's alpha value has been used to examine the reliability of the scale used in the questionnaire. Cronbach's alpha value 0.70 (or greater) indicates that questionnaire used is reliable (Gliem, J. A., Gliem, R. R. 2003; George, Mallery 2002).
The survey instrument consisted of 3 parts. The first part gathered information about socio-demographic characteristics such as age, sex, occupation, educational qualification, and income. The second part collected data about trip characteristics such as frequency of walk trip, walking distance, the purpose of walk trips and time taken for walk trips. The third part focused on the pedestrians' perception about the sidewalks. It gathered information about the pedestrians' level of agreement/satisfaction with given statements about the quality of each environmental attributes that affect PLOS of sidewalks. For example, statements like "there is so much traffic along the street where I work/live which makes it difficult to walk". The respondents were asked to state their level of agreement with provided attributes of walking along sidewalks on a 5 point Likert scale ranging from strongly disagree to strongly agree. The attributes of the PLOS of sidewalk considered in the survey were identified by critically reviewing various design guidelines, sidewalk assessment tools, etc. The attributes considered are traffic volume, traffic speed, availability of crossing facilities, presence of buffer, shaded walk, pedestrian amenities, presence of bus shelters, police patrolling, street lighting, Closed-Circuit TeleVision (CCTV) cameras, wider sidewalks, good sidewalk surface, absence of obstructions, absence of encroachment, continuous sidewalks, cleaner sidewalks and facilities for people with disability.

\section{Results}

\subsection{Descriptive statistics}

On observing the total user sample, it was comprehended that $58 \%$ data was collected from men and $42 \%$ from women. With regard to age, $14 \%$ reported age less than 18 years, followed by $47 \%$ respondents between 18 to 45 years, $31 \%$ between 45 to 60 and rest are aged greater than 60 . In terms of occupation, $25 \%$ respondents are students, $23 \%$ working in public service, $24 \%$ from the private sector, $12 \%$ are housewives. Almost one-third of the respondents were not ready to disclose their income. Almost $40 \%$ of respondents walk up to 10 min daily, about $43 \%$ respondents walk 11 to $20 \mathrm{~min}$ daily and only $17 \%$ respondents' walk for a long time i.e. for 21 to $60 \mathrm{~min}$. Regarding the purpose of walking, most of the respondents (32\%) walk as a part of exercise and health maintenance, about $15 \%$ of respondents walk for work.

\subsection{Exploratory factor analysis}

EFA was performed to assess the relationships between attributes and the latent factors. EFA is used to identify the number of factors underlying the variations in and correlation among them, items that load onto a particular factor and also removes the items that do not load into any of the extracted factors. EFA was performed for the perception scores obtained for 17 attributes using PCA to perform factor extraction and varimax rotation in SPSS 
software (https://www.ibm.com/analytics/spss-statisticssoftware). The items with factor loadings 0.5 or higher were considered more important in the study. During the iteration, following factors were deleted, i.e. (1) factors with loadings less than 0.5 , (2) factors with low commonalities, and (3) factors, which are cross loaded (Gliem, J. A., Gliem, R. R. 2003), therefore 2 factors such as availability of crossing facilities and presence of buffer, are removed. The cross loaded attributes like cleaner sidewalks were not removed because the loading difference with two factors was greater than 0.2 . The pedestrian perception data about the PLOS gained using various attributes were reduced to a four-factor solution (Hair et al. 2013). This four-factor solution has an eigenvalue greater than one and it explained a satisfactory variance of $60.204 \%$. The Bartlett test got a significant value $(p<0.001)$ of 1945.0 that confirmed the overall significance of correlation matrix. KMO value of 0.8 indicates that sampling is adequate. After attributes were grouped, the factors were named as, "Safety", "Comfort and convenience", "Security" and "Mobility and infrastructure". A scree plot (Figure 2) displays the eigenvalues associated with a component or factor versus the number of the component or factor. This scree plot shows that 4 of those factors explain most of the variability because the line starts to straighten after factor 4 . The remaining factors explain a very small proportion of the variability and are likely unimportant. Table 2 illustrates the EFA results on factors, in which factor 1, "Mobility and infrastructure" encompasses seven attributes such as good sidewalk surface, wider sidewalks, the presence of bus shelters, continuous sidewalks, the absence of encroachment, pedestrian amenities and facilities for people with disability

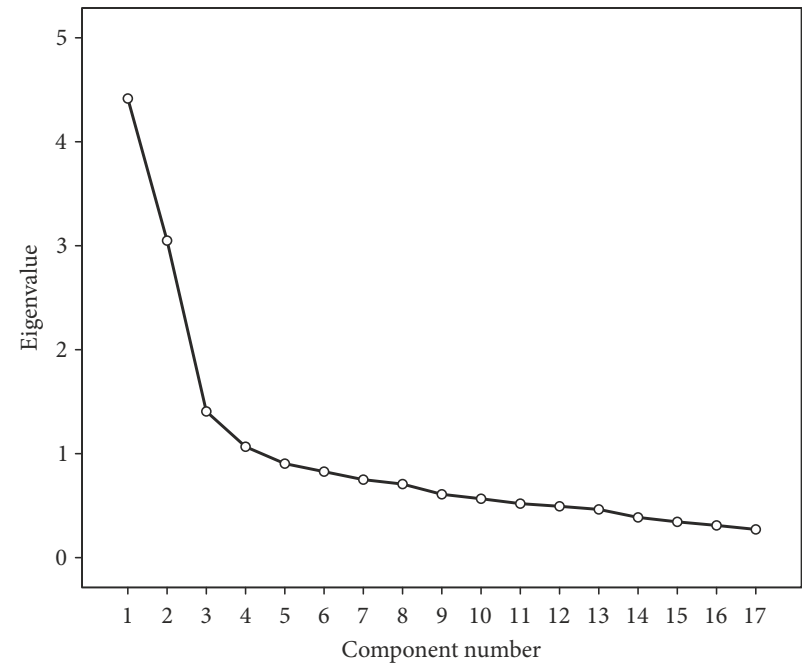

Figure 2. Scree plot displaying number of factors versus eigenvalue

with EFA loading values between 0.571 to 0.819 . Finally, factor 2, "Comfort and convenience", consists of two items such as the absence of obstructions and cleaner sidewalks with EFA loadings 0.733 and 0.638 respectively. Factor 3 is pedestrian "Security" from crime and theft, involving three factors like police patrolling, CCTV cameras, street lighting carrying EFA loadings from 0.636 to 0.827 . Factor 3 is the pedestrian "Safety" from traffic includes two items such as traffic speed and traffic volume with loading 0.911 and 0.897 respectively. Cronbach's alpha obtained greater than 0.70 for each factor shows the reliability of the questionnaire (Gliem, J. A., Gliem, R. R. 2003). As mentioned

Table 2. Results of EFA of perceptions on perceived PLOS

\begin{tabular}{|c|c|c|c|c|c|c|}
\hline Attributes & Communalities & Loadings $^{*}$ & Variance [\%] & Cronbach's alpha & Skewness & Kurtosis \\
\hline \multicolumn{7}{|c|}{ Factor 1: Mobility and infrastructure } \\
\hline Good sidewalk surface & 0.679 & 0.819 & & \multirow{6}{*}{0.828} & -0.650 & -0.665 \\
\hline Wider sidewalks & 0.579 & 0.736 & & & -0.795 & -0.252 \\
\hline Presence of bus shelters & 0.48 & 0.682 & & & -0.910 & -0.361 \\
\hline Continuous sidewalks & 0.512 & 0.593 & 22.077 & & -0.517 & -0.927 \\
\hline Absence of encroachment & 0.397 & 0.581 & & & -0.454 & -0.870 \\
\hline Pedestrian amenities & 0.390 & 0.571 & & & -0.528 & -0.714 \\
\hline \multicolumn{7}{|c|}{ Factor 2: Comfort and convenience } \\
\hline $\begin{array}{l}\text { Facilities for people } \\
\text { with disability }\end{array}$ & 0.651 & 0.791 & & \multirow{3}{*}{0.700} & 1.08 & 0.151 \\
\hline Absence of obstructions & 0.628 & 0.733 & 13.252 & & 0.025 & -1.02 \\
\hline Cleaner sidewalks & 0.653 & 0.638 & & & -0.259 & -1.03 \\
\hline \multicolumn{7}{|c|}{ Factor 3: Security } \\
\hline Police patrolling & 0.716 & 0.827 & & \multirow{3}{*}{0.651} & 0.040 & -1.36 \\
\hline CCTV cameras & 0.523 & 0.715 & 12.45 & & 0.121 & -1.16 \\
\hline Street lighting & 0.533 & 0.636 & & & -0.959 & -0.227 \\
\hline \multicolumn{7}{|c|}{ Factor 4: Safety } \\
\hline Traffic speed & 0.857 & 0.911 & 12.424 & \multirow{2}{*}{0.784} & -0.650 & -0.665 \\
\hline Traffic volume & 0.831 & 0.897 & & & -0.555 & -0.890 \\
\hline
\end{tabular}

Note: ${ }^{*}$ EFA loading $\geq 0.5$ is accepted. 
earlier, Cronbach's alpha value of 0.70 or greater than 0.70 indicates the reliability scale of questionnaire. Table 2 shows the internal consistency reliability results of the items grouped by the factor. The coefficients of Cronbach's alpha value were greater than 0.70 for all items except factor "Security", which is having a value very close to 0.70 . The moderate values of alpha for the factors shows that questions were reliable.

\subsection{Normality tests}

The study tested normality of the data set using skewness and kurtosis. The skewness and kurtosis are measured for each item to conduct normality assessment. The absolute value of skewness and kurtosis between -1.5 to +1.5 . The skewness and kurtosis values for all items (as in Table 2) are acceptable indicating that all items are normally distributed. Therefore, skewness and kurtosis value between -1.365 to +1.083 show that data is normally distributed. Thus, it confirmed the eligibility of applying SEM approach for the corresponding data set.

\subsection{Identification and influence of latent constructs}

SEM was estimated using ML method on the basis of 502 observations. AMOS 20.0 package (Arbuckle 2011) is used to calibrate the SEM model. Fourteen observed variables were used to calibrate the model. The model identified four latent exogenous variables named "Safety", "Security", "Mobility and Infrastructure" and "Comfort and convenience" (Figure 2) representing the main aspects of the PLOS of sidewalks. Table 3 and Figure 3 displays the relationships between latent variables. The first column represents the variables of the model such as latent endogenous and exogenous model. The next columns specify different statistics of the relationships such as Standardized Regression Weights (Std.R.W.), Standard Error (S.E.), the Critical Ratio (C.R.) and the Probability value (P). The C.R. and $p$-value are used for evaluating its parameter significance. The C.R. is the ratio of parameter estimate and S.E. and it tests the hypothesis that whether the parameter is statistically different from zero. When C.R. $>1.96$ for a regression weight, that attribute is significant at 0.05 level and $p$-value 0.000 indicates significance is smaller than 0.001 . The Std.R.W. are used for comparing the effects of a given endogenous variable in a single group study. Most of the standard regression weights are reasonable, i.e. above 0.5 except two of them obtained lower value 0.46 and 0.48 for the parameters facilities for people with disability and CCTV cameras. In the structural model, the relation between endogenous latent variable PLOS is explained by four latent exogenous variables like safety, security, mobility and comfort, which are found to be significant at 0.001 . Thus, these factors are considered as acceptable and satisfying parameters statistically that can be applied to measure the PLOS of sidewalks. The results found that "Security" obtained the maximum value of estimate $(\gamma=$ $0.60)$, followed by "Comfort and convenience" $(\gamma=0.52)$, "Safety" $(\gamma=0.50)$ and "Mobility and infrastructure" $(\gamma=$ $0.39)$. There is high correlation noted between comfort and mobility latent variables with loading, $\gamma=0.725$ that signifies the high similarity of observed factors under these two constructs (Figure 2). These two constructs can be combined as one since they are having high correlation loading (Awang 2012), but the model gives better factor loadings and fit indices than without combining comfort and mobility constructs.

Table 3. Measurement model for SEM

\begin{tabular}{|c|c|c|c|c|c|c|c|}
\hline \multicolumn{2}{|r|}{ Latent exogenous variable } & \multicolumn{2}{|r|}{ Observed exogenous variable } & \multirow{2}{*}{$\begin{array}{c}\text { Std.R.W. } \\
0.841 \\
\end{array}$} & \multirow{2}{*}{$\begin{array}{c}\text { S.E. } \\
0.045\end{array}$} & \multirow{2}{*}{$\begin{array}{c}\text { C.R. } \\
18.68 \\
\end{array}$} & \multirow{2}{*}{$\begin{array}{c}\mathrm{P} \\
0.000\end{array}$} \\
\hline & Cofotr & $x 1$ & Traffic volume & & & & \\
\hline$\zeta_{1}$ & Sarety & $x 2$ & Traffic speed & 0.842 & 0.048 & 17.54 & 0.000 \\
\hline \multirow{3}{*}{$\xi_{2}$} & \multirow{3}{*}{ Security } & $x 3$ & Police patrolling & 0.793 & 0.057 & 13.91 & 0.000 \\
\hline & & $x 4$ & Street lighting & 0.531 & 0.047 & 11.29 & 0.000 \\
\hline & & $x 5$ & CCTV cameras & 0.481 & 0.052 & 9.25 & 0.000 \\
\hline \multirow{6}{*}{$\xi_{3}$} & \multirow{6}{*}{ Mobility and infrastructure } & $x 6$ & Wider sidewalks & 0.699 & 0.043 & 16.25 & 0.000 \\
\hline & & $x 7$ & Continuous sidewalks & 0.635 & 0.042 & 15.11 & 0.000 \\
\hline & & $x 8$ & Absence of encroachment & 0.528 & 0.045 & 11.73 & 0.000 \\
\hline & & $x 9$ & Good sidewalk surface & 0.760 & 0.044 & 17.27 & 0.000 \\
\hline & & $x 10$ & Pedestrian amenities & 0.514 & 0.044 & 11.68 & 0.000 \\
\hline & & $x 11$ & Presence of bus shelters & 0.577 & 0.041 & 14.07 & 0.000 \\
\hline \multirow{3}{*}{$\xi_{4}$} & \multirow{3}{*}{ Comfort and convenience } & $x 12$ & Cleaner sidewalks & 0.851 & 0.046 & 18.50 & 0.000 \\
\hline & & $x 13$ & Facilities for people with disability & 0.461 & 0.048 & 9.60 & 0.000 \\
\hline & & $x 14$ & Absence of obstructions & 0.657 & 0.048 & 13.68 & 0.000 \\
\hline \multicolumn{2}{|r|}{ Latent endogenous variable } & \multicolumn{2}{|r|}{ Latent exogenous variable } & Std.R.W. & S.E. & C.R. & $\mathrm{P}$ \\
\hline \multirow{4}{*}{$\eta$} & \multirow{4}{*}{ PLOS } & $\xi_{1}$ & Safety & 0.498 & 0.102 & 4.88 & 0.000 \\
\hline & & $\xi_{2}$ & Security & 0.596 & 0.169 & 3.52 & 0.000 \\
\hline & & $\xi_{3}$ & Mobility and infrastructure & 0.394 & 0.054 & 7.24 & 0.000 \\
\hline & & $\xi_{4}$ & Comfort and convenience & 0.516 & 0.08 & 6.45 & 0.000 \\
\hline
\end{tabular}




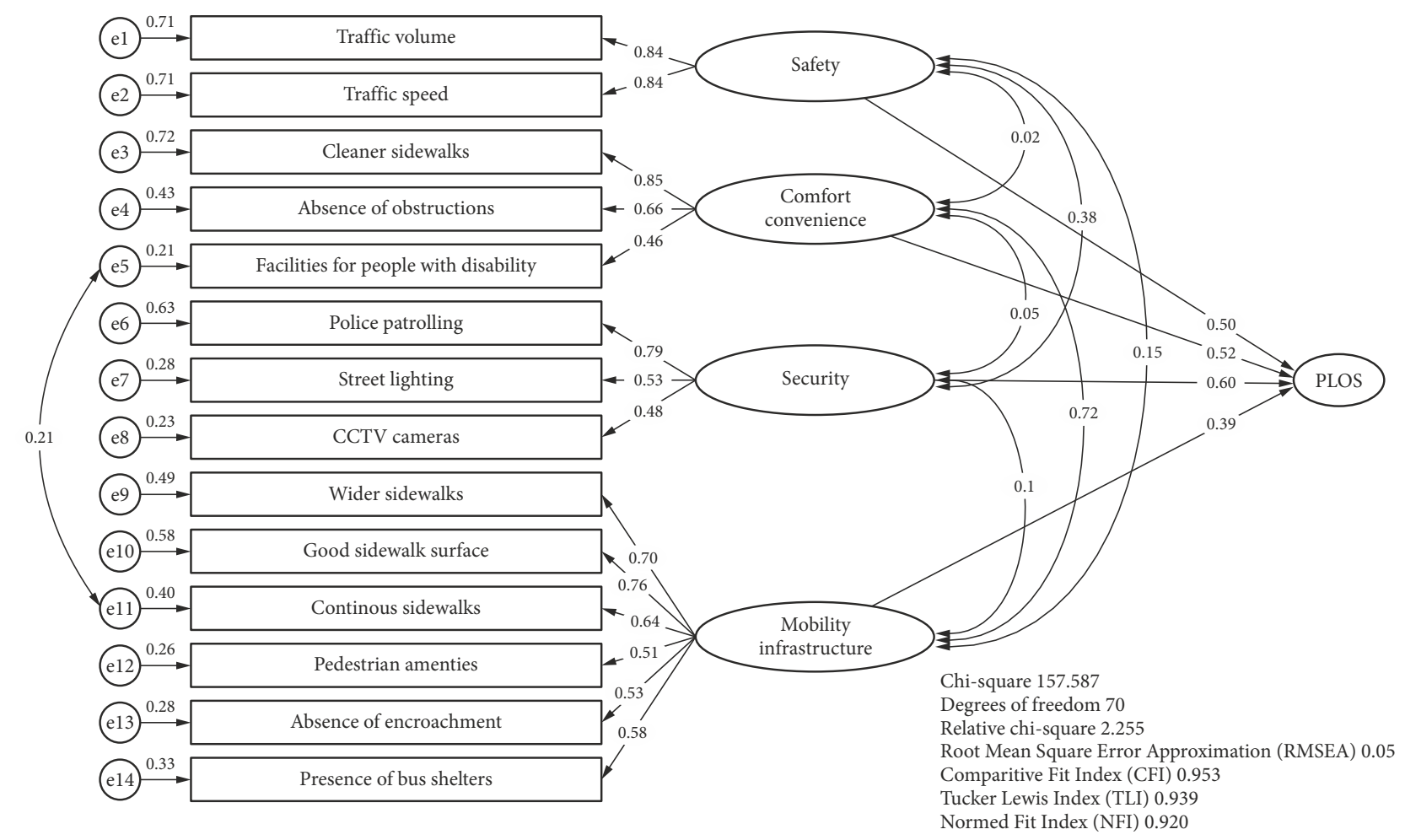

Figure 3. Structural equation model for PLOS

\subsection{Fit indexes}

A variety of indexes were used to check the goodness of SEM models. The fit index are to be improved to acquire better results. They are improved by dropping the factors or by identifying the redundant items in the measurement model. The redundancy can be assessed through Modification Indexes (MI). The redundancy can be removed by either by deleting one of the two redundant items or by setting errors of two redundant items as a free parameter i.e. correlating the errors of two redundant items (Gerbing, Anderson 1984; Awang 2012). The items with low multiple $R^{2}$ (less than 0.20) should be removed from the analysis as this is an indication of very high levels of error (Hooper et al. 2008). A final model of this study included two correlated measurement error between $10^{5}$ and $10^{11}$. The final model results are presented in Figure 3 illustrated goodness of fit as follows: chi-square, $\chi^{2}$ of 157.85 , degrees of freedom $(d f)$, 70 with $p$-value $<0.001, \frac{\chi^{2}}{d f}=2.255$. Using corresponding equations given below, SEM fit in-

dexes obtained are calculated. Various SEM fit indexes are explained below.

Bentler and Bonett (1980) introduced Normed Fit Index (NFI). The index measures the model by comparing the $\chi^{2}$ value of the model to be evaluated to the $\chi^{2}$ of the null or baseline model. In baseline model, all measured variables are uncorrelated. The index range between 0 and 1 where a good fit is obtained at the value NFI $\geq 0.90$ :

$$
N F I=1-\frac{\chi_{M}^{2}}{\chi_{B}^{2}},
$$

where: $\chi_{M}^{2}$ is the chi-square value of the proposed model; $\chi_{B}^{2}$ is the chi-square value of the base model.

By using the Equation (4), NFI value is calculated as 0.92 , which is inacceptable range.

The Comparative Fit Index (CFI) is one of the popularly reported fit index, which does not get affected by sample size (Fan et al. 1999). This index was introduced by Bentler (1990). The CFI is given by:

$$
\begin{aligned}
& C F I=1-\frac{\hat{\delta}_{M}}{\hat{\delta}_{B}} ; \\
& \hat{\delta}_{M}=\max \left(\chi_{M}^{2}-d f_{M}, 0\right) ; \\
& \hat{\delta}_{B}=\max \left(\chi_{B}^{2}-d f_{B}, 0\right),
\end{aligned}
$$

where: $\hat{\delta}_{M}$ and $\hat{\delta}_{B}$ is the degree of misspecification of evaluated model and baseline mode respectively.

CFI evaluates the performances of evaluated model to the baseline model. A value of $C F I \geq 0.95$ is presently recognized as indicative of good fit (Hu, Benteler 1999). In this study, CFI obtained is 0.953 , which is greater than acceptable value indicating good model fit.

Tucker Lewis Index (TLI) or Non-Normed Fit Index (NNFI) is an incremental index. In some cases, where sample size is smaller, the value of NNFI can give poor fit (Bentler, Bonett 1980). Let $\frac{\chi^{2}}{d f}$ is the ratio of chi-square 
to degree of freedom, where TLI is given by:

$$
T L I=\frac{\frac{\chi_{B}^{2}}{d f_{B}}-\frac{\chi_{M}^{2}}{d f_{m}}}{\frac{\chi_{B}^{2}}{d f_{B}}-1} .
$$

$T L I \geq 0.9$ indicates acceptable model fit. TLI value obtained this study is 0.939 is in its acceptable range of fit.

Root Mean Square Error of Approximation (RMSEA) is an absolute measure of fit based on the non-centrality parameter was first developed by Steiger and Lind (1980). With $N$ as the sample size and $d f$ is the degree of freedom, RMSEA is calculated as:

$$
R M S E A=\frac{\sqrt{\chi^{2}-d f}}{\sqrt{d f \cdot(N-1)}} .
$$

RMSEA $\leq 0.06$ is accepted as good fit $(\mathrm{Hu}$, Bentler 1999). The RMSEA value obtained in the study is 0.05 , indicate that model is of good fit.

Thus, all statistical values of the measurement model are good and acceptable except $\chi^{2}$ significance. $\chi^{2}$ should have a have $p$-value $>0.05$ for the acceptable fit (Schermelleh-Engel et al. 2003). Since the $\chi^{2}$ statistic is sensitive to sample size, tends to reject the hypothesis of $p$-value $\geq 0.05$ and thus no longer relied upon as a basis for acceptance and rejection (Schermelleh-Engel et al. 2003; Vandenberg 2006). Thus, overall model can be considered as a good with its large sample size.

\section{Discussion}

The results found that perceived PLOS of sidewalks is most influenced by pedestrian satisfaction in terms of "Security" followed by other factors like "Comfort and convenience", "Safety" and "Mobility and infrastructure". Table 3 provides the summary of SEM results that first condenses the effects of observed variables on the latent variables and then in resulting effects on PLOS. The security construct has the largest effect on PLOS, represented by the measured variables like presence of CCTV cameras, police patrolling and the street lighting. Among these measured variables, police patrolling has the highest factor loading indicating a high level of pedestrian satisfaction with police security along the sidewalks which provides them a secure environment for walking. The observed variable street lighting has also positively influence "Security" but with low loading indicating the street lighting facilities along sidewalks are not provided adequately up to the mark of pedestrian satisfaction. The presence of CCTV camera has the lowest factor loading among all the observed variables. "Comfort and convenience" is the second latent variable that influenced the PLOS after "Security". The "Comfort and convenience" latent variable is better explained by three measured variables like cleaner sidewalks, facilities for people with disability. Among all variables considered for the PLOS, cleaner sidewalks received the highest loading indicating that the cleanliness of sidewalks as an important factor for measuring "Comfort and convenience". Thus, the cleaner sidewalks, police security are some of the important factors that influence pedestrian satisfaction of walking environment thereby PLOS. The aforementioned results are consistent with the results of previous studies that are based on SEM analysis of pedestrian satisfaction (Said et al. 2017; Hidayat et al. 2010). Attribute absence of obstruction has a comparatively less loading comfort factor when compared to cleaner sidewalks which indicate the walking gets restricted to pedestrians due to the obstructions present along the sidewalk in the form of trees, poles, hoardings, signboards, etc.

The latent constructs "Mobility" has the least factor loading on PLOS. Thus PLOS is least influenced by their satisfaction with latent construct "Mobility and infrastructure". This variable is explained by six observed variables like wider sidewalks, good sidewalk surface, continuous sidewalks, pedestrian amenities and the absence of encroachment and presence of bus shelters. Among these variables, sidewalk surface received a highest factor loading on "Mobility and infrastructure", which indicates the pedestrian satisfaction on the sidewalk surface is the most influential factor to measure mobility. Pedestrians are satisfied with the attributes such as sidewalk surface, which matches with the study area environment. The factor "Pedestrian amenities" attained least factor loading confirming the least pedestrian satisfaction on this factor. Other factors that are showing low loadings specify the low pedestrian satisfaction indicating that they have less effect on PLOS. The level of satisfaction with safety is a latent construct variable having a second lowest influence on PLOS. In safety construct, the traffic volume and traffic speed attained high factor loadings indicating that they are the two dominant observed factors that can be used to quantify the level of pedestrian satisfaction on feeling safe from the traffic while walking on sidewalks. Similar to the results of the study, there are other studies that stated that traffic speed and volume influences PLOS (Landis et al. 2001; Christopoulou, Pitsiava-Latinopoulou 2012). A high loading on these factors signifies that traffic volume and traffic speed are high along the road stretch, which highly retards them from negatively affects walking. These factors highly impact pedestrians' satisfaction on safety from traffic that consequently degrades the PLOS.

Policy interventions have to be formulated to improve pedestrians' satisfaction of these built environmental factors, which will, in turn, improve the PLOS. Since the level of satisfaction of the latent variable "Security" has a high influence on the PLOS, it is necessary to target the observed variables under the "Security". The factor loading of the observed variables on the latent variable "Security" implies that any change in these variables can impact the PLOS of sidewalks. Therefore, by improving the pedestrians' satisfaction with the security in terms of police patrolling would enhance PLOS of sidewalks. Kerala is the highest cognizable crime rate reported state in India as per the National Crime Record Bureau (NCRB 2016), there- 
fore, it is important to provide a safe and secure walking environment to people through police deployment along sidewalks. This can improve pedestrians' satisfaction in a secure environment from crimes or theft, thus would enhance PLOS. Similarly, the PLOS can also be enhanced by improving street lighting and installing CCTV cameras. It is always better to adjust the improvements of factors based on their ease and cost of installation. Therefore, providing street lights will be more cost efficient and easier task than the installation of CCTV cameras and can give better results on PLOS improvement. Police of Thiruvananthapuram city have already reported that most of the street lights mainly in crime-prone areas are not working (TNN 2017). This can ascertain as one of the main reasons for people to avoid walking that consequently affect PLOS. Therefore, it is important to repair, maintain the existing street lights and install more street lights along the sidewalks that would improve PLOS of sidewalks. The improvements in such factors should be achieved immediately through the permission from the National Highway Authority of India to encourage the walking and pedestrian satisfaction on the safer walking environment thereby gaining improved PLOS.

Interventions aiming at improving the comfort level of walking are necessary for the enhancement of qualitative PLOS that encourage people to walk more. The pedestrians' satisfaction in terms of comfort can be improved by improving sidewalk cleanliness, removing obstructions and providing facilities for people with disability. Among these variables, targeting sidewalk cleanliness would be an easier assignment and can give better results with lower costs. Also by removing the obstructions along sidewalks would lead to a better impact on PLOS. These improvements can be achieved by regular supervision of municipal staffs on the private waste management companies responsible for cleaning the streets of the city. The "Comfort and convenience" variable has observed to have a high correlation with variable "Mobility and infrastructure". Therefore, factors under mobility can be jointly improved with the factors under comfort for the enhancement of PLOS. Under "Mobility and infrastructure" that got high loadings are sidewalk surface, sidewalk width, continuous sidewalks, etc. The sidewalk surface can be improved by filling the cracks and bumps with low cost and good quality materials, which will further improve on the pedestrians' satisfaction level. However, according to the present conditions of the city, the sidewalk width cannot be increased because of the space and cost constraints majorly at commercial zones. And removal of obstructions such as flex boards, hoardings, banners, etc., along sidewalks can improve the utility of existing sidewalks consequently enhancing mobility in a better way than the sidewalk widening.

The policy interventions on safety also can influence the PLOS of sidewalks. In the case of Thiruvananthapuram city, improving pedestrians' satisfaction with safety in terms of traffic volume and traffic speed, intuitively, by reducing traffic volume and traffic speed would lead to increase in pedestrian satisfaction of safety. Therefore, by strictly enforcing traffic rules and speed limits along the road networks of the city, it would be positively impact LOS at low-cost. However, the impact of these interventions will be smaller when compared to the interventions aiming security latent variable because of its high influence on PLOS than any other factors.

\section{Conclusions}

The study focused on the assessment of factors involving perceived PLOS of sidewalks based on 17 parameters in ten zones of Thiruvananthapuram city (India). The study demonstrated that SEM can be used as an alternative method to identify the latent variables that describe a series of attributes assessing PLOS. SEM was chosen because it has proved to be an appropriate technique to deal with complex perceptions of pedestrians about quality of sidewalks. The poor conditions of pedestrian facilities, encroachments by construction sites and street vendors, obstructions in the form of sign boards, hoardings, etc., necessitated the need to find the most coherent interventions in order to enhance pedestrian's satisfaction, that can upgrade PLOS of sidewalks. In this study, 502 pedestrians from ten different zones across Thiruvananthapuram city were interviewed about the quality of service of sidewalks based on various built environment factors. EFA grouped parameters into four groups with 14 parameters (three parameters were deleted) described as "Security", "Safety", "Comfort and convenience", and "Mobility and infrastructure". Then a SEM has been then developed to find the factors that highly impact the PLOS. In the structural model, the relation between endogenous latent variable such as PLOS is explained by four latent exogenous variables, which are found to be significant at 0.001 . The results stated that the 14 attributes can be used to assess the satisfaction level of those 4 latent variables at 0.001 significance level. Thus, these attributes are considered as acceptable and satisfying parameters that can be used to measure the PLOS of sidewalks. The results found that security obtained the highest standard regression weight $(\lambda=0.60)$, followed by "Comfort and convenience" $(\lambda=$ $0.52)$, "Safety" $(\lambda=0.50)$ and "Mobility and infrastructure" $(\lambda=0.39)$. The study identified the parameters such as police patrolling, street lighting, cleaner sidewalks, sidewalk obstructions, sidewalk surface, traffic speed, traffic volume have an evident impact on the PLOS. Pedestrians are more concerned with the security against crime or theft while walking along sidewalks of the city. Policy interventions have to be formulated to improve people's satisfaction on various built environment factors, which will, in turn, can improve the PLOS. Police patrolling especially at night, improving street lighting and installing CCTV cameras, etc. would enhance pedestrians' satisfaction towards security, which would considerably improve the PLOS of sidewalks. However, there are limitations to the extent to which these implications can be adopted due to high installation cost. Therefore, it is always better to adjust the improvements of factors based on their ease and cost of 
installation. Thus, provision of installing more street lights will be more cost efficient and easier task than the installation of CCTV cameras will better enhance the level of service of sidewalks. Similarly, improvement of pedestrians' satisfaction to mobility can be done cost effectively by improving sidewalk surface and removing obstructions of existing sidewalks instead of widening sidewalks, which can be tougher task considering space constraints of the city.

The results of the study provide a significant data for interpreting which are the aspects of the walking environment that most influences the PLOS. This information can help planners to prepare new strategies, policy interventions that enhance the quality of sidewalks. The results provide valuable insights regarding the pedestrians' satisfaction to the built environment factor that affects PLOS. It is expected that these proposed suggestion and implications, if applied to the existing sidewalk infrastructure will contribute more walkability and consequently improve the liveability of the street.

The study has constructed a model according to Thiruvananthapuram context. The results of the study can be adopted in the settings of other similar million plus cities where a lack of effective planning and high population growth had induced various transport-related problems. These loadings can be used to build weighted scores for the level of service assessment. The model results can be used for calculating the PLOS on the basis of the standard regression weights and error terms estimated for the latent exogenous variables by SEM formulation. The values of this latent exogenous variables can estimate from the standard regression weights and errors of observed variables. Thus, PLOS threshold level can be proposed for the city based on the pedestrian satisfaction over sidewalk facilities. This study only considered micro scale attributes of the built environment that affect walkability. In the further study macro-scale factors like residential density, land use density, intersection density, floor area ratio etc. can also be included.

\section{References}

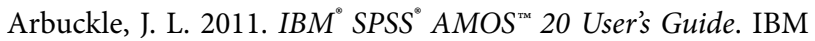
Corporation. 680 p. Available from Internet: ftp://public.dhe. ibm.com/software/analytics/spss/documentation/amos/20.0/ en/Manuals/IBM_SPSS_Amos_User_Guide.pdf

Asadi-Shekari, Z.; Moeinaddini, M.; Zaly Shah, M. 2013. Disabled pedestrian level of service method for evaluating and promoting inclusive walking facilities on urban streets, Journal of Transportation Engineering 139(2): 181-192.

https://doi.org/10.1061/(ASCE)TE.1943-5436.0000492

Awang, Z. 2012. Structural Equation Modeling Using AMOS Graphic. UiTM Press. 167 p.

Barker, L. 2012. Exploring the Relationship between Walkability and the Built Environment: a Case Study of Three Intersections in Seattle's University District. MSc Thesis. University of Washington, US. 49 p. Available from Internet: https://digital. lib.washington.edu/researchworks/handle/1773/20287

Bentler, P. M. 1990. Comparative fit indexes in structural models, Psychological Bulletin 107(2): 238-246.

https://doi.org/10.1037/0033-2909.107.2.238
Bentler, P. M.; Bonett, D. G. 1980. Significance tests and goodness of fit in the analysis of covariance structures, Psychological Bulletin 88(3): 588-606.

https://doi.org/10.1037/0033-2909.88.3.588

Bollen, K. A. 1989. A new incremental fit index for general structural equation models, Sociological Methods \& Research 17(3): 303-316. https://doi.org/10.1177/0049124189017003004

Christopoulou, P.; Pitsiava-Latinopoulou, M. 2012. Development of a model for the estimation of pedestrian level of service in Greek urban areas, Procedia - Social and Behavioral Sciences 48: 1691-1701. https://doi.org/10.1016/j.sbspro.2012.06.1144

Clifton, K. J.; Livi Smith, A. D.; Rodriguez, D. 2007. The development and testing of an audit for the pedestrian environment, Landscape and Urban Planning 80(1-2): 95-110. https://doi.org/10.1016/j.landurbplan.2006.06.008

CPD. 2011. Population Census 2011. Census Population Data (CPD), India. Available from Internet:

http://www.census2011.co.in

De Oña, J.; De Oña, R.; Eboli, L.; Mazzulla, G. 2013. Perceived service quality in bus transit service: a structural equation approach, Transport Policy 29: 219-226.

https://doi.org/10.1016/j.tranpol.2013.07.001

Dixon, L. B. 1996. Bicycle and pedestrian level-of-service performance measures and standards for congestion management systems, Transportation Research Record: Journal of the Transportation Research Board 1538: 1-9.

https://doi.org/10.1177/0361198196153800101

Dowling, R.; Flannery, A.; Landis, B.; Petritsch, T.; Rouphail, N.; Ryus, P. 2008. Multimodal level of service for urban streets, Transportation Research Record: Journal of the Transportation Research Board 2071: 1-7. https://doi.org/10.3141/2071-01

Eboli, L.; Mazzulla, G. 2007. Service quality attributes affecting customer satisfaction for bus transit, Journal of Public Transportation 10(3): 21-34. http://doi.org/10.5038/2375-0901.10.3.2

Fan, X.; Thompson, B.; Wang, L. 1999. Effects of sample size, estimation methods, and model specification on structural equation modeling fit indexes, Structural Equation Modeling: A Multidisciplinary Journal 6(1): 56-83. https://doi.org/10.1080/10705519909540119

Gallin, N. 2001. Quantifying pedestrian friendliness: guidelines for assessing pedestrian level of service, Road and Transport Research 10(1): 47-55.

George, D.; Mallery, P. 2002. SPSS for Windows Step by Step: A Simple Guide and Reference, 11.0 Update. Allyn \& Bacon. 400 p.

Gerbing, D. W.; Anderson, J. C. 1984. On the meaning of withinfactor correlated measurement errors, Journal of Consumer Research 11(1): 572-580. https://doi.org/10.1086/208993

Gliem, J. A.; Gliem, R. R. 2003. Calculating, interpreting, and reporting Cronbach's alpha reliability coefficient for Likerttype scales, in 2003 Midwest Research to Practice Conference in Adult, Continuing, and Community Education, 8-10 October 2003, Columbus, OH, US, 82-88.

Goldberger, A. S. 1972. Structural equation methods in the social sciences, Econometrica 40(6): 979-1001.

https://doi.org/10.2307/1913851

Golob, T. F. 2003. Structural equation modeling for travel behavior research, Transportation Research Part B: Methodological 37(1): 1-25. https://doi.org/10.1016/S0191-2615(01)00046-7

Hair, J. F.; Black, W. C.; Babin, B. J.; Anderson, R. E. 2013. Multivariate Data Analysis. Pearson. 729 p.

Hidayat, N.; Choocharukul, K.; Kishi, K. 2010. Investigating structural relationships among pedestrian perception, behavior, traffic, and level of service, Journal of Japan Society of Civil Engineers 27(1): 99-108. https://doi.org/10.2208/journalip.27.99 
Holmes-Smith, P.; Coote, L.; Cunningham, E. 2006. Structural Equation Modelling: from the Fundamentals to Advanced Topics. Melbourne: School Research, Evaluation and Measurement Services (SREAMS). 218 p.

Hooper, D.; Coughlan, J.; Mullen, M. R. 2008. Structural equation modelling: guidelines for determining model fit, Electronic Journal of Business Research Methods 6(1): 53-60.

Hu, L.-T.; Bentler, P. M. 1999. Cutoff criteria for fit indexes in covariance structure analysis: Conventional criteria versus new alternatives, Structural Equation Modeling: a Multidisciplinary Journal 6(1): 1-55. https://doi.org/10.1080/10705519909540118

IRC: 103-2012. Guidelines for Pedestrian Facilities. New Delhi, The Indian Roads Congress (IRC).

Jensen, S. U. 2007. Pedestrian and bicyclist level of service on roadway segments, Transportation Research Record: Journal of the Transportation Research Board 2031: 43-51.

https://doi.org/10.3141/2031-06

Johnson, M. D.; Anderson, E. W.; Fornell, C. 1995. Rational and adaptive performance expectations in a customer satisfaction framework, Journal of Consumer Research 21(4): 695-707. https://doi.org/10.1086/209428

Khisty, C. J. 1994. Evaluation of pedestrian facilities: beyond the level-of-service concept, Transportation Research Record: Journal of the Transportation Research Board 1438: 45-50.

Kim, S.; Choi, J.; Kim, S. 2013. Roadside walking environments and major factors affecting pedestrian level of service, International Journal of Urban Sciences 17(3): 304-315. https://doi.org/10.1080/12265934.2013.825422

Kim, S.; Park, S.; Lee, J. S. 2014. Meso- or micro-scale? Environmental factors influencing pedestrian satisfaction, Transportation Research Part D: Transport and Environment 30: 10-20. https://doi.org/10.1016/j.trd.2014.05.005

Krejcie, R. V.; Morgan, D. W. 1970. Determining sample size for research activities, Educational and Psychological Measurement 30(3): 607-610. https://doi.org/10.1177/001316447003000308

Landis, B. W.; Vattikuti, V. R.; Ottenberg, R. M.; McLeod, D. S.; Guttenplan, M. 2001. Modeling the roadside walking environment: pedestrian level of service, Transportation Research Record: Journal of the Transportation Research Board 1773: 82-88. https://doi.org/10.3141/1773-10

Mitra-Sarkar, S. S. 1994. A Method for Evaluation of Urban Pedestrian Spaces. PhD Dissertation. University of Pennsylvania, Philadelphia, PA, US. 388 p. Available from Internet: https://repository.upenn.edu/dissertations/AAI9521086

Muraleetharan, T.; Adachi, T.; Uchida, K.-E.; Hagiwara, T.; Kagaya, S. 2004. A study on evaluation of pedestrian level of service along sidewalks and at crosswalks using conjoint analysis, Infrastructure Planning Review 21(3): 727-735. https://doi.org/10.2208/journalip.21.727

Muthén, B.; Kaplan, D. 1985. A comparison of some methodologies for the factor analysis of non-normal Likert variables, British Journal of Mathematical and Statistical Psychology 38(2): 171-189. https://doi.org/10.1111/j.2044-8317.1985.tb00832.x

NATPAC. 2014. Annual Report 2013-'14. National Transportation Planning and Research Centre (NATPAC), India. $141 \mathrm{p}$. Available from Internet: http://www.natpac.kerala.gov.in/index.php/publications/annual-report

NCRB. 2016. Crime in India 2015: Compendium. National Crime Record Bureau (NCRB), Ministry of Home Affairs, Government of India. 222 p. Available from Internet: http:// ncrb.gov.in/StatPublications/CII/CII2015/FILES/Compendium-15.11.16.pdf
Parida, P.; Najamuddin, D.; Parida, M. 2007. Planning, design and operation of sidewalk facilities in Delhi, Highway Research Bulletin 77: 81-95.

Pikora, T. J.; Bull, F. C.; Jamrozik, K.; Knuiman, M.; Giles-Corti, B.; Donovan, R. J. 2002. Developing a reliable audit instrument to measure the physical environment for physical activity, American Journal of Preventive Medicine 23(3): 187-194. https://doi.org/10.1016/S0749-3797(02)00498-1

Said, M.; Abou-Zeid, M.; Kaysi, I. 2017. Modeling satisfaction with the walking environment: the case of an urban university neighborhood in a developing country, Journal of Urban Planning and Development 143(1).

https://doi.org/10.1061/(ASCE)UP.1943-5444.0000347

Schermelleh-Engel, K.; Moosbrugger, H.; Müller, H. 2003. Evaluating the fit of structural equation models: test of significance and descriptive goodness-of-fit measures, Methods of Psychological Research Online 8(2): 23-74.

Steiger, J. H.; Lind, J. C. 1980. Statistically based tests for the number of common factors, in Annual Spring Meeting of the Psychometric Society, 28-30 May 1980, Iowa City, IA, US.

TNN. 2017. Lack of street lights poses threat to motorists and pedestrians, The Times of India, 7 February 2017. Available from Internet: https://timesofindia.indiatimes.com/city/ kochi/lack-of-street-lights-poses-threat-to-motorists-andpedestrians/articleshow/57008220.cms

Vale, D. S.; Pereira, M. 2016. Influence on pedestrian commuting behavior of the built environment surrounding destinations: A structural equations modeling approach, International Journal of Sustainable Transportation 10(8): 730-741. https://doi.org/10.1080/15568318.2016.1144836

Vandenberg, R. J. 2006. Statistical and methodological myths and urban legends: where, pray tell, did they get this idea?, Organizational Research Methods 9(2): 194-201. https://doi.org/10.1177/1094428105285506

Walk Score . 2018. Walk Score Methodology. Available from Internet: https://www.walkscore.com/methodology.shtml

Zainol, R.; Ahmad, F.; Nordin, N. A.; Aripin, A. W. M. 2014. Evaluation of users' satisfaction on pedestrian facilities using pair-wise comparison approach, IOP Conference Series: Earth and Environmental Science 18(1): 012175. https://doi.org/10.1088/1755-1315/18/1/012175 